\title{
The Construction and Application of a Personalized Teaching Space in Mobile English
}

\author{
https://doi.org/10.3991/ijet.v13i11.9610 \\ Ning Jin $(\bowtie)$ \\ Fuyang Normal College, Anhui Fuyang, China \\ ning 34 @ 163. com \\ Zhengkun Yan \\ Anhui University of Finance and Economics, Bengbu, China
}

\begin{abstract}
This paper designs the construction dimension of College English individualized teaching space, and constructs its system architecture combining with the requirements of teaching and learning cloud space. Secondly, it expounds the four application strategies of learning cloud space in College English Teaching: individualized spatial dynamic allocation strategy, self-taught strategy under the support of experience, and based on the ubiquitous environment. Fragmented learning strategy and language learning oriented interactive dialogue strategy; finally, it introduces three application patterns in College English Teaching in the light of learning cloud space: overturning, subject inquiry learning and mixed teaching, and verifying the use effect of cloud space through case studies. The results show that customized learning cloud space and its application can improve the efficiency of College English teaching and promote students'mastery of English application skills.
\end{abstract}

Keywords-Internet, personalization, English teaching

\section{$1 \quad$ Introduction}

Advances in technology affect the development and change of society. After the nicheization of the agricultural society, education is shifting towards the popularization of industrial society and the individualization of post-industrial society. In the agricultural society, education is only exclusive to a few aristocrats or religious figures. Teaching is mostly a form of mentoring. The form of teaching organization is mainly individual teaching, and the content of education is still the transmission of human experience. Teaching methods are mainly based on experience, and teachers use their own experience to teach students. With the emergence of large industrial production of machines and the rapid development of productivity, the structure and scale of education have also changed with the development of the economy. Education has entered a modern stage. Class teaching replaces individual teaching and becomes the most basic form of teaching organization. However, education in the era of industrialized production focuses on the transfer of knowledge and skills to cultivate the large number of labor 
producers needed for large-scale industrial production. The teacher's teaching practice is to instill the required labor knowledge into the students. It is a simple and effective method to train students' labor skills through repeated training. Since the 1990s, information technology represented by computers and networks has developed rapidly, and human society has entered an information age in the post-industrial era. As a kind of information, knowledge becomes more easily disseminated and queried through the network. Everyone can be a producer or a communicator of knowledge. At this time, the status of teachers as knowledge monopolies has gradually decreased with the advent of the Internet age. The traditional classroom teaching model is constantly challenged and looks forward to change.

Compared to the traditional desktop Internet, the mobile Internet has several distinct features. The first one is convenience. The mobile internet is a three-dimensional network. The seamless coverage of GPRS, EDGE, 3G, 4G and WLAN or WIFI enables mobile terminals to communicate over any of the above forms. The second is portability. The basic carrier of the mobile Internet is a mobile terminal. As the name suggests, these mobile terminals are not just smart phones, tablets, but also smart glasses, watches, clothing, accessories and other personal belongings. They are part of the human body and can be used anytime and anywhere. The third is immediacy. Thanks to the above convenience, people can make full use of the fragmentation time in life and work, and accept and process all kinds of information on the Internet. The important information and timeliness information will not be missed. The fourth is orientation. The location service can not only locate the location of the mobile terminal, but also determine the location of the next step according to the trend of the mobile terminal. Therefore, related services have reliable positioning and orientation. The fifth is accuracy. Mobile terminals are highly personalized. Especially for smartphones, each phone number is precisely pointed to a clear individual. The mobile Internet can provide more precise and personalized services for different individuals. The sixth is sensitivity. This is not only reflected in the touch level of the mobile terminal screen, but more importantly in photography, video, QR code scanning, as well as gravity sensing, magnetic field sensing, motion sensing, temperature, humidity sensing, and even human heart induction, blood pressure sensing and pulse sensing. These six characteristics constitute a completely different user experience ecosystem between mobile Internet and desktop Internet.

At present, with the development and popularization of mobile internet and smart mobile terminals, mobile learning has a better use environment. In informal learning, mobile learning is becoming a popular learning method. In the classroom teaching, its ubiquitous learning field has become a natural extension and expansion of classroom teaching. Mobile learning and course teaching are integrated to better serve teaching. This has become the focus of research. 


\section{State of the art}

Research on mobile learning begins at abroad. These studies are mainly based on projects. In summary, the research on mobile learning in foreign countries mainly focuses on the following aspects:

Mejbri et al. [1] first proposed the concept of "mobile learning." Mobile learning is the product of the development of distance learning to a certain stage. With the development of mobile technology, mobile learning will definitely make a big change in the field of education. Learners can use the mobile phone to learn at any time and any place. Rimale et al. [2] proposed the concept of mobile learning and explained mobile learning. Afterwards, many experts and scholars also put forward their own understanding of mobile learning according to project practice, including the definition and characteristics of mobile learning.

Christiansen et al. [3] mainly research the development and design of mobile intelligent terminals. The mobile intelligent terminal can adapt to the needs of mobile learning and has certain computing power. It can share the work of some servers to reduce network burden, reduce learning costs and improve learning efficiency. At present, smartphones are becoming popular, and more and more people are using smartphones to learn. High-quality mobile intelligent terminals not only bring a good learning experience, but also enhance the learner's recognition of mobile learning.

In terms of mobile learning systems and platforms, Tayan et al. [4] focused on specialized learning systems and learning platforms for supporting mobile learning. Learners experience powerful learning capabilities on mobile learning systems and platforms.

Yasmin et al. [5] explored the application of short messages in mobile learning. Mobile learning is characterized by flexibility and convenience. However, due to various support technologies and limitations of terminal equipment, as well as the high cost of communication, people are encouraged to study mobile learning methods that are more acceptable to everyone. The application of short messages is one of them. In daily life, short messages are often used by people as a means of communication, and their convenience, flexibility, and familiarity with the public arouse the interest of researchers. Some studies have applied it to education and teaching to carry out experiments, and the preliminary results are good. In such research, because of convenience and flexibility, short messages serve as a common means of assisting instruction to convey course information, schedules, and other important information. As a means of communication between teachers and students, its convenience is higher than E-mail. Therefore, text messages are loved by teachers and students.

The study of mobile learning involves a wide range of fields. In corporate training, mobile learning is used to increase efficiency and save costs. Mobile learning is linked to concepts such as lifelong learning and collaborative learning. Mobile learning resources are designed and mobile learning support technologies are developed. Standardization of mobile learning was studied. Mobile learning, which originated in foreign countries, is developing rapidly with unpredictable momentum. With the deepening of mobile learning and related technologies and theoretical research, as well as the acceptance and recognition of mobile learning, the advantages of mobile learning will become more and more obvious. 
China's mobile learning research started late. Different from the research situation abroad, China's research is theory first, and then some practical research is carried out. By searching the academic literature on the topic of "mobile learning" on the Chinese journal network CNKI, it is found that domestic research on mobile learning started late. The earliest research was the introduction of the article "From Distance Learning to E-Learning to Mobile Learning" by Irish scholar expert Desmond Keegan in the fifth issue of Open Education Research in 2000. The idea of D-learning to E-learning to Mlearning was proposed.

Ji et al. [6] introduced the research status, theory and philosophical basis of mobile learning in detail in "Mobile Learning and Its Theoretical Basis", and pointed out that mobile learning has a broad development prospect as a new learning paradigm.

Zhang and Wang [7] conducted an in-depth analysis of the concept, research status, typical projects and key issues of mobile learning. This is the first detailed review paper in China. The following stages of research prospects include research on mobile learning system related technologies, software development research on mobile learning terminals, mobile learning curriculum development research, mobile learning system standardization research, and mobile learning teaching model research.

Huang et al. [8] introduced mobile learning overview, related technologies, application models, design theories and methods, and supporting technologies and educational trends in mobile learning.

In summary, at present, China has a large proportion of theoretical research in mobile learning research, but there is little localization and in-depth innovation research. In terms of technical research, scholars have tried to introduce various high-tech, but the key issues of this technology in mobile learning applications have not been broken. In terms of application and practice research, some valuable cases have been formed, but they have not yet been fully summarized and improved. With the attention of experts and scholars on mobile learning, the research scope of mobile learning is expanded. As the scope expanded, the nature of mobile learning was abandoned and new perspectives were blindly increased.

\section{$3 \quad$ Methodology}

\subsection{The basis of existing mobile learning theory}

Activity theory: The unification of consciousness and activity is one of the most basic assumptions of activity theory. They believe that people can only achieve cognitive goals through conscious meaning formation and interaction activities. Activity theory is based on the activity system as the basic unit for analyzing social culture. The activity system consists of six elements: subject, tool, object, division of labor, community and rules. It can be divided into four subsystems: production, distribution, communication and consumption. Figure 1 shows the active system. 


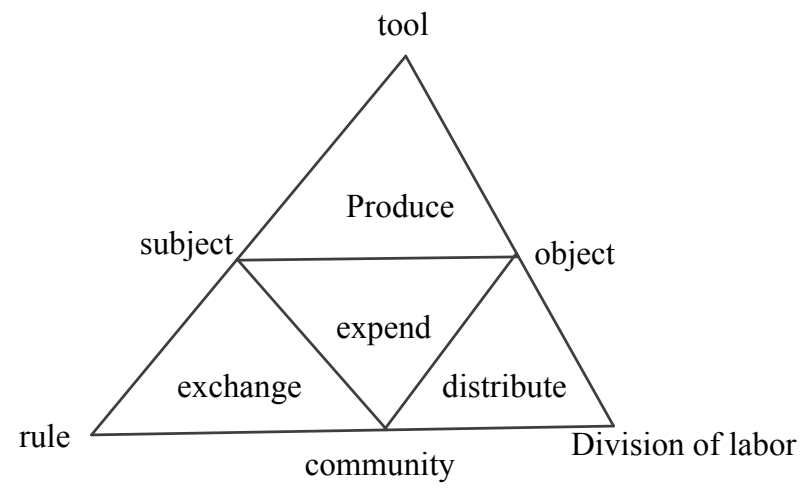

Fig. 1. Active system

The main function of the production subsystem is to convert the object into a result under the intermediary of tools or symbols.

The consumption subsystem describes the community that exists with the subject. It may play a role in the ability and resource occupation of the object conversion process.

The allocation subsystem refers to the connection of the activity object and the community through the division of labor according to social laws or expectations.

The communication subsystem refers to the rules for the members of the community to regulate activities under the constraints of the common agreement.

Informal learning: "Informal learning" is relative to formal schooling or continuing education. It refers to the form of learning that accepts new knowledge at the time and place of informal study, such as work, life, and social interaction. Learning behaviors include salons, reading, gatherings, and playing.

Situational cognition theory: Situational cognition emphasizes social networks and activity systems of real behavior. If the learning environment or the learner's mind is studied in a single way, the mechanism of learning cannot be well explained. Based on the mutual coordination between the researcher and the situation, the learning style is correctly recognized. Therefore, the prominent feature of situational cognition is to explore personal cognition based on larger physical and social contexts.

\subsection{Design ideas of mobile English teaching mode}

The research ideas of the model of the English mobile learning system are introduced. The necessary premises and basic theory are discussed. Then, the design principles and characteristics of the college English mobile learning system model are introduced.

The theoretical model of mobile learning and the needs of a personalized English learning system were analyzed. It provides the basis and support for the construction of the mobile English learning system model. However, the effective mobile learning system model needs to analyze the ontology characteristics of the English subject and the new curriculum reform requirements, and the students' personalized mobile learning rules. Figure 2 shows the design ideas of mobile English teaching mode. 


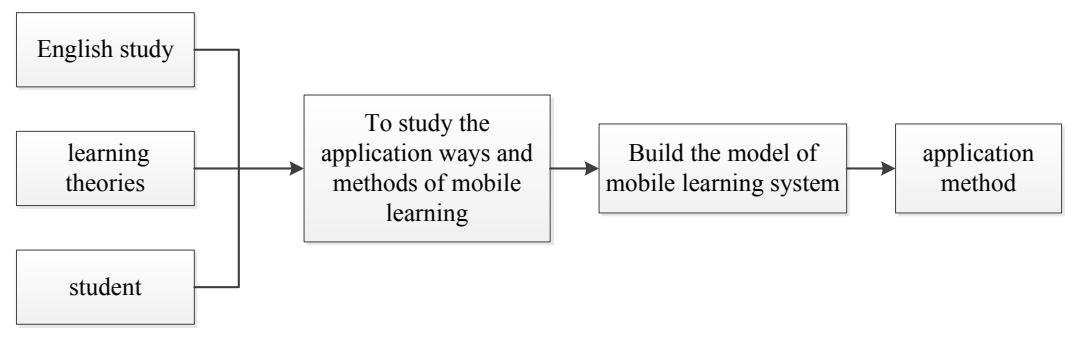

Fig. 2. Design ideas of mobile English teaching mode

Mobile learning theory models and student needs for mobile learning systems are analyzed. According to the new English course and the law of students' mobile learning, a gamification, humanization and personalized English mobile learning system model is proposed. Using this model, students can learn anywhere, anytime, through multiple types of terminals. This tailors the learning plan and the learning content for the learner. Students and teachers can exchange ideas in real time. Students' learning progress and mastery can be tracked and analyzed, and the learning plan and content can be revised accordingly, and individualized work can be consolidated and evaluated.

\subsection{Design of teaching mode of mobile learning}

On the one hand, the mobile learning environment provides a good real-time communication platform for students; on the other hand, it provides good learning aids and course-related resources. Generally, the teaching process consists of three stages: before class, during class, and after class. Combined with the teaching design model framework and the characteristics of the mobile learning environment, a personalized English teaching design framework based on the mobile learning environment was designed. The design framework will extend the time and space of learning through a mobile learning environment. The original teaching model was changed. Pre-class, inclass and after-school teaching activities are connected to form a complete teaching model. Figure 3 shows the teaching mode in mobile learning environment.

There are three user roles in the system model: student, teacher, and administrator. The three user roles interact with each other. Students are the center of the system. They can get test questions and collaborate on learning. The teacher guides and assists the students in learning and conducts supervision and evaluation, and carries out teaching design and educational management. The administrator is responsible for maintaining the system and managing student and teacher information. Teachers can work as administrators. Figure 4 shows the role analysis in the model.

In the personality and learning module, the functions of evaluation, recording, and reminding are explained. Based on the learning effect curve and the learner's ranking, the results were evaluated. The specific situation of learners is visualized in the form of charts and tables. The feedback module is especially suitable for mobile learning as a supplement to formal learning, so that teachers can supervise and guide the progress of students' learning. 


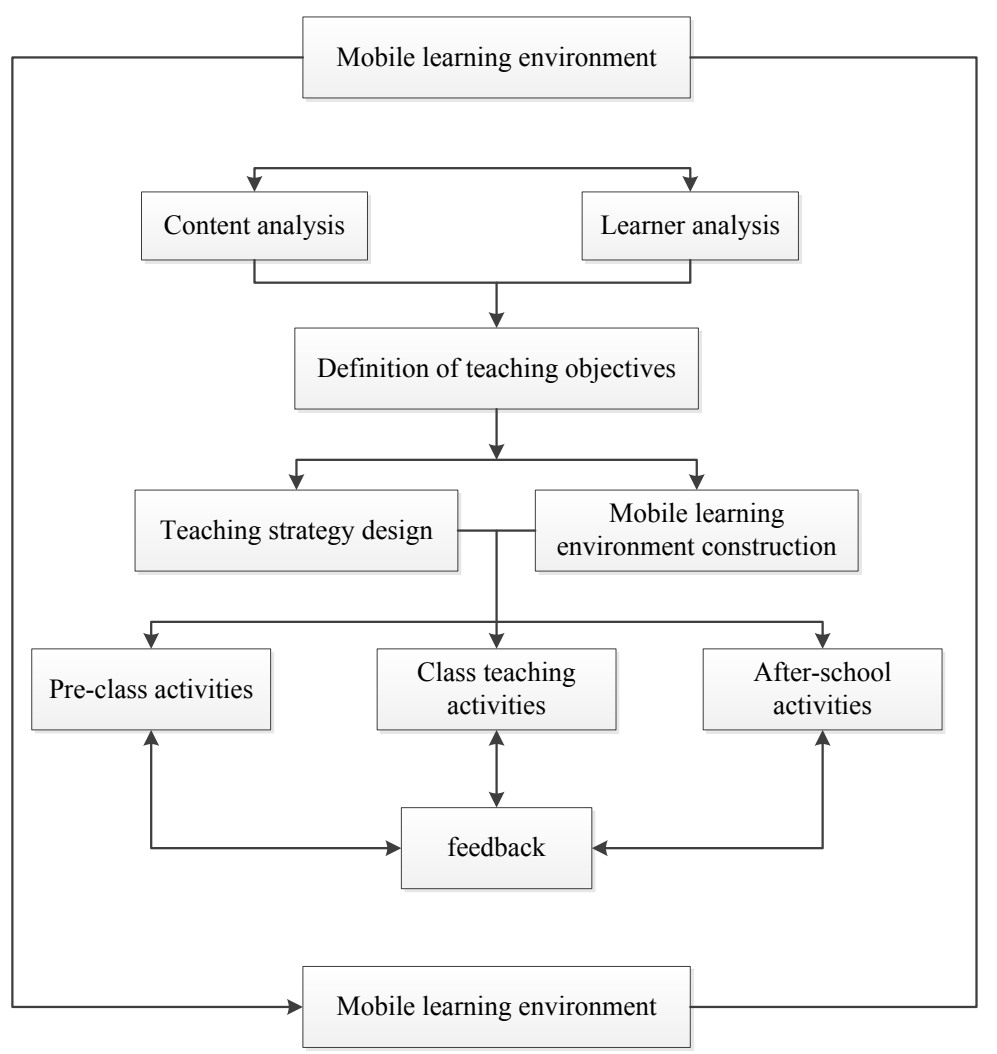

Fig. 3. Teaching mode in mobile learning environment

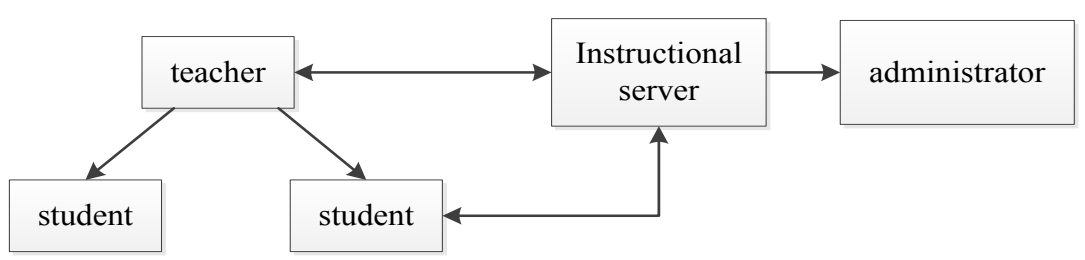

Fig. 4. Role analysis in the model

To have good versatility, the management module includes both the educational management module and the system management module. If the model is not used for formal teaching supplements, the functions of the system management section are only used. The system management module is mainly used to manage system users and various types of routine maintenance. The educational management module provides educational management functions similar to traditional teaching systems. The information collection module refers to collecting student information or opinions by means of short message or connection browsing, and can view results, analysis, and decision in the background. In addition, it also can be used for course study investigation and class 
activity opinions collection. These two modules involve a lot of database operations such as adding, retrieving, and updating. To achieve an efficient response of the system with limited bandwidth, the database should be reasonably organized, and the algorithm of the database should be efficient. At the same time, the module also involves a large amount of information presentation. To achieve hierarchical and structured information layout in the case of limited screen size of mobile terminals, the page organization algorithm should be scientific, and information partitioning should be reasonable.

\section{$4 \quad$ Result analysis and discussion}

\subsection{Case background}

In July 2018, a practical teaching application study was conducted in the fifth grade of an experimental primary school in Shaanxi Province in 4 weeks. This school is a key elementary school in the region. At present, in the teaching conditions and applications of information technology, the classroom is equipped with large-screen multimedia devices that can connect to the Internet to support teachers in playing multimedia courseware and displaying Internet resources in the classroom. However, the school's English teachers did not use the mobile Internet to improve teaching methods.

\subsection{Front end analysis}

To better implement the teaching model and understand the students' English learning status, 52 students were investigated and 52 valid questionnaires were collected. Figure 5 shows the statistical results.

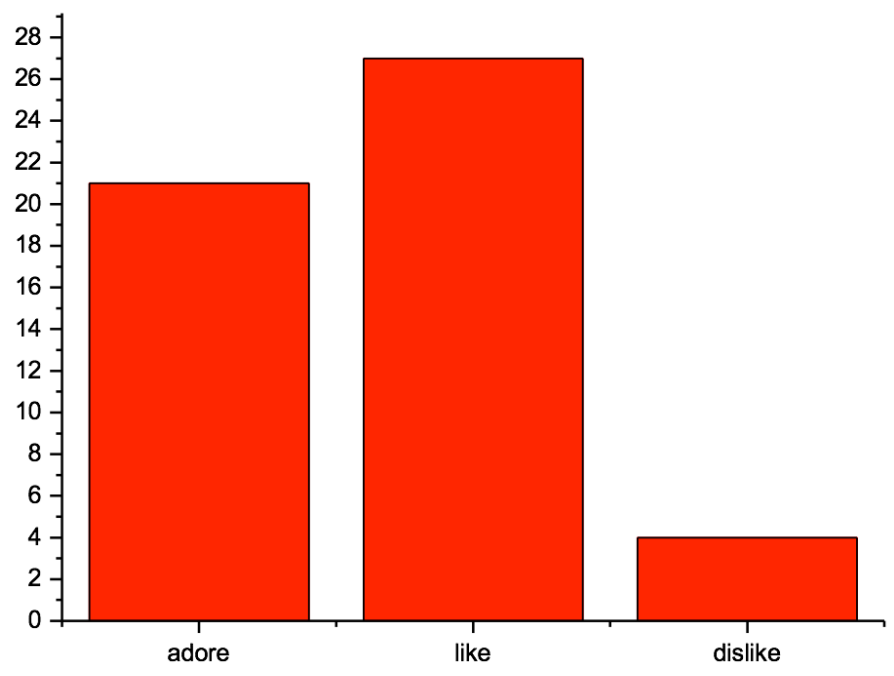

Fig. 5. Students' interest in English 
As can be seen from Figure 5, 92.3\% of the students like English classes. $40.38 \%$ of students like English classes very much, and $51.92 \%$ of students have a little interest in English classes. Only 7.70\% of students said they didn't like English classes. This reflects the English learning status of the class students. Most students do not have the hard time to learn English and like to take English classes. A few students do not like to learn English because they are not good at learning. The students who did not dare to speak in English accounted for up to $42.31 \%$, followed by $40.38 \%$ of students who could not pronounce correctly, and only $17.31 \%$ of students who were restricted by vocabulary. Therefore, dialogue and communication are the biggest difficulties for students in learning English.

\subsection{Instructional strategy design}

Before class, students should preview the textbook content. In the classroom, students should learn key knowledge. After class, students should review and consolidate the content of the class. Before the class, the students are learning independently. In the class, teaching, inquiry and collaborative teaching modes are combined. After class, the teaching methods are practice, testing, and discussion.

\subsection{Construction of the mobile learning environment}

The mobile learning environment requires the conditions of hardware and software. The hardware requires a mobile terminal such as a smartphone and a connectable mobile network. According to the questionnaire, smartphones have become popular among students. Therefore, the smart phone is a hardware device of the mobile learning environment, and the smart phone must be able to connect to the mobile internet.

Software is the two mainstream systems of current smart mobile devices. Some English teaching apps of Android and IOS are used as software resources for mobile learning environments, such as WeChat, elementary school English electronic reading materials, NetEase's dictionary and Hujiang Happy Words. In addition, through a researchbased online platform - Questionnaire Star, some of the test questions were sent to the students through the WeChat group to answer questions online.

Hardware terminal: A smartphone or tablet with Andriod and IOS operating systems.

Access network conditions: 2G, 3G, 4G and WIFI.

\subsection{Feedback evaluation and summary analysis}

In practice, 52 students conducted four tests. Test scores are analyzed by average grade and standard deviation. Figure 6 shows the average score. Figure 7 shows the standard deviation.

As can be seen from Figure 6 and Figure 7, the average score of the test is on the rise, and the standard deviation of the test scores is declining, which fully reflects the student's learning changes. It shows that after a period, the mobile teaching system has improved English scores. At the same time, the score gap between students is narrowed. The English learning scores of all students are improved. 


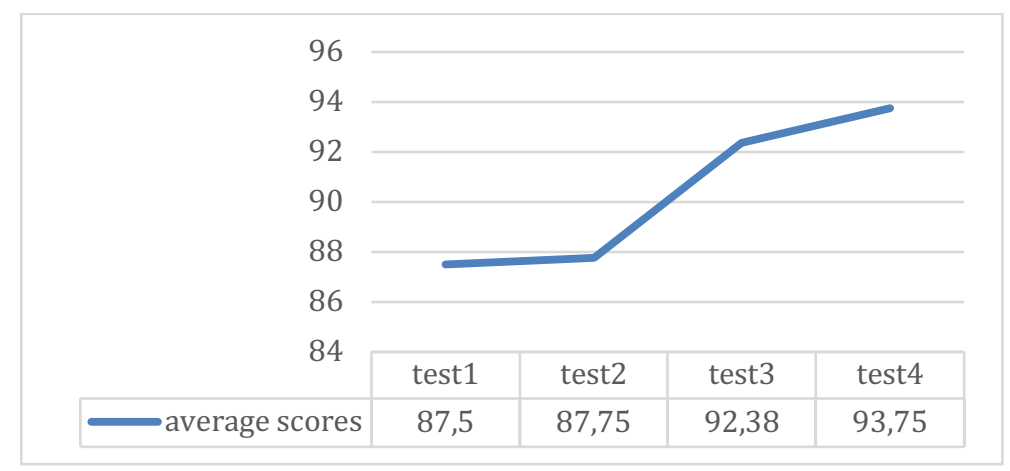

Fig. 6. Average score

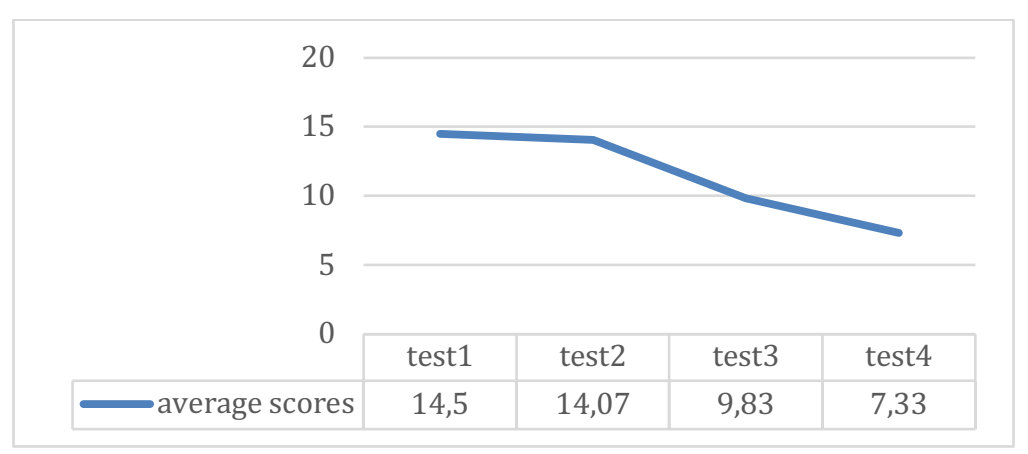

Fig. 7. Standard deviation

\subsection{Implementation summary}

The teaching effect in the mobile learning environment is good. On the one hand, teaching methods are changing, and teaching is not just in the classroom. After class, teaching becomes ubiquitous. The teaching form can be a group teaching in the classroom, or it can be individual tutoring on the WeChat platform. Teachers receive timely and effective feedback from the teaching. In addition, the role of the teacher is not static. More importantly, teachers have become the promoters of students in the process of independent learning, and help and guide students to learn English.

On the other hand, student learning is also changing. Like teachers, students don't just complete the learning tasks in the classroom. After class, students still have learning tasks. Students can receive individual guidance and Q\&A from the teacher at any time. Students can use the electronic textbooks on the mobile phone to preview and review the text content under the guidance of the teacher. They can also do some specific exercises in the text. Students use electronic dictionaries and word software to remember words. Using the WeChat platform, students communicate and share knowledge, which is impossible in traditional teaching environments and models. The mobile teaching mode brings great convenience to students' learning, and personalized learning is realized. 
Although the teaching implementation of the mobile learning environment is good, there are still some problems. First, regarding the ideological concept of mobile learning, some teachers or parents do not understand mobile learning or use mobile phones to generate resistance, which hinders the advancement of learning to a certain extent. The second is the teacher's time investment problem. Because the teacher is also responsible for the self-learning of the students after the class, the students learn the question answerers, which requires the teachers to invest time and interact with the students and exchange counseling. Most teachers still have a lot of family affairs to deal with after work, which affects teaching to some extent. The third is that students do not have enough self-consciousness to ask questions.

\section{Conclusions}

The research status and related theories of mobile learning at home and abroad are summarized. The environment, concepts, characteristics, theoretical basis and related technical support of mobile learning are introduced. The personalized English teaching model in the mobile learning environment was designed. This provides a certain reference for other teaching modes. English teaching in a mobile learning environment is feasible and has achieved good results. The limitations of the traditional teaching model are broken. Teachers' personalized counseling for students is achieved. Teachers guide students to learn independently and construct knowledge systems. At the same time, students can get the guidance of teachers and the acquisition of learning resources anytime and anywhere.

\section{References}

[1] Mejbri Y, Khemaja M, Raies K. (2018). Towards a new requirements' definition methodology using ontologies for Pervasive Games Based Learning Systems. Eai En-dorsed Transactions on Serious Games, 4(14): 153-533

[2] Rimale Z, Habib B E, Tragha A. (2016). Survey on the Use of the Mobile Learning Based on Mobile Cloud Computing. International Journal of Interactive Mobile Tech-nologies, 10(3): 35 https://doi.org/10.3991/ijim.v10i3.5672

[3] Christiansen M, Greene C, Pardo S. (2017). A New, Wireless-enabled Blood Glucose Monitoring System That Links to a Smart Mobile Device: Accuracy and User Perfor-mance Evaluation. Journal of Diabetes Science \& Technology, 11(3): 567 https://doi.org/10.1177/ $\underline{1932296817691301}$

[4] Tayan O, Ghembaza E K, Al-Oufi K. (2017). Design and Architecture of a Location and Time-based Mobile-Learning System: A Case-Study for Interactive Islamic Con-tent. International Journal of Advanced Computer Science \& Applications, 8(3): 302 https://doi.org/10.14569/IJACSA.2017.080342

[5] Yasmin F, Banu B, Zakir S M. (2016). Positive influence of short message service and voice call interventions on adherence and health outcomes in case of chronic disease care: a systematic review. Bmc Medical Informatics \& Decision Making, 16(1): 46 https://doi.org/10.1186/s12911-016-0286-3 
[6] Ji H, Ling J, Mccarthy V L. (2016). Successful aging in the United States and china: a theoretical basis to guide nursing research, practice, and policy. Journal of Transcul-tural Nursing, 26(2): 129 https://doi.org/10.1177/1043659614526257

[7] Zhang Y L, Wang X K. (2017). LBS Mobile Learning System Based on Android Plat-form. 11: 10005

[8] Huang J H, Lin Y R, Chuang S T. (2017). Elucidating user behavior of mobile learn-ing: A perspective of the extended technology acceptance model. Electronic Library, 25(25): 586599

\section{Authors}

Ning Jin is with the School of Foreign Languages, Fuyang Normal College, Anhui Fuyang, 236037, China (ning34@163.com).

Zhengkun Yan is with the School of Languages and Media, Anhui University of Finance and Economics, Bengbu, 233030, China.

Article submitted 15 September 2018. Resubmitted 12 October 2018. Final acceptance 24 October 2018. Final version published as submitted by the authors. 